\title{
Breve reflexión sobre los arquitectos y la cartografía cultural de chile
}

Brief thought of the architects
and the "cultural cartography of chile"

María Isabel Pavez R.

\section{$<$ Resumen $>$}

A partir de la lectura de diversos estudios emprendidos por el Consejo Nacional de la Cultura y las Artes en el objetivo de establecer una "cartografía cultural de chile", se constata que en los momentos en que tiende a incrementarse significativamente el número de arquitectos ejerciendo en Chile, dichos estudios no incluyen a los arquitectos (y demás trabajadores que les acompañan en su labor) como actores culturales, aún cuando sus obras que han alcanzado cierto nivel de excelencia son registradas como productos culturales patrimoniales. A partir de esta constatación se reflexiona sobre algunas de las posibles causas de tal omisión.

$<$ Abstract $>$

St udi es done by the Nati onal Comission of Culture and Art, that established a cultural cartography of Chile, ascertain that architects and their staff are not included as cultural actors, even though thei $r$ work of excellence is registered as cultural heritage. Based on this fact, one can anal yze some of the possible causes for such an omission.

<Palabras clave>

CARTOGRAFIA CULTURAL DE CHILE, PATRIMONIO CULTURAL, ACTORES CULTURALES, ARQUITECTURA Y URBANISMO

$<$ Key words $>$

CULTURAL CARTOGRAPHY OF CHI LE, CULTURAL HERI TAGE, CULTURAL ACTORS, ARCHI TECTURE, URBANI SM

Las portadas de estos libros fueron usadas con fines ilustrativos.
Los estudios del Consejo Nacional de la Cultura y las Artes

El proyecto "Cartografía Cultural de Chile", emprendido por el Consejo Nacional de la Cultura y las Artes, permitiría identificar y ubicar territorialmente a los actores culturales, las manifestaciones culturales y el patrimonio natural y cultural del país, además de profundizar en la especificidad de cada territorio y de cada práctica ${ }^{1}$.
Por "Actor Cultural", definieron sus autores a personas, agrupaciones de personas 0 instituciones, cuyo desempeño contribuye a la creación o reproducción, distribución, exhibición, comercialización, difusión y conservación de prácticas u objetos culturales, y que son reconocidos por su comunidad como tales. Estos actores se agruparon en seis áreas de creación: música, artes visuales, artes audiovisuales, artes escénicas, artes coreográficas y literatura, más un área transversal2 . Por "Territorio Cultural" se entendió el espacio donde la actividad cultura

CHILE, GOBIERNO DE CHILE, Consejo Nacional de la Cultura y las Artes. Cartografía Cultural de Chile. Lecturas Cruzadas. Santiago: Publicaciones Unidad de Estudios, agosto de 2003. Año 1, №1, 101 págs., cuadros, gráficos, glosario. 

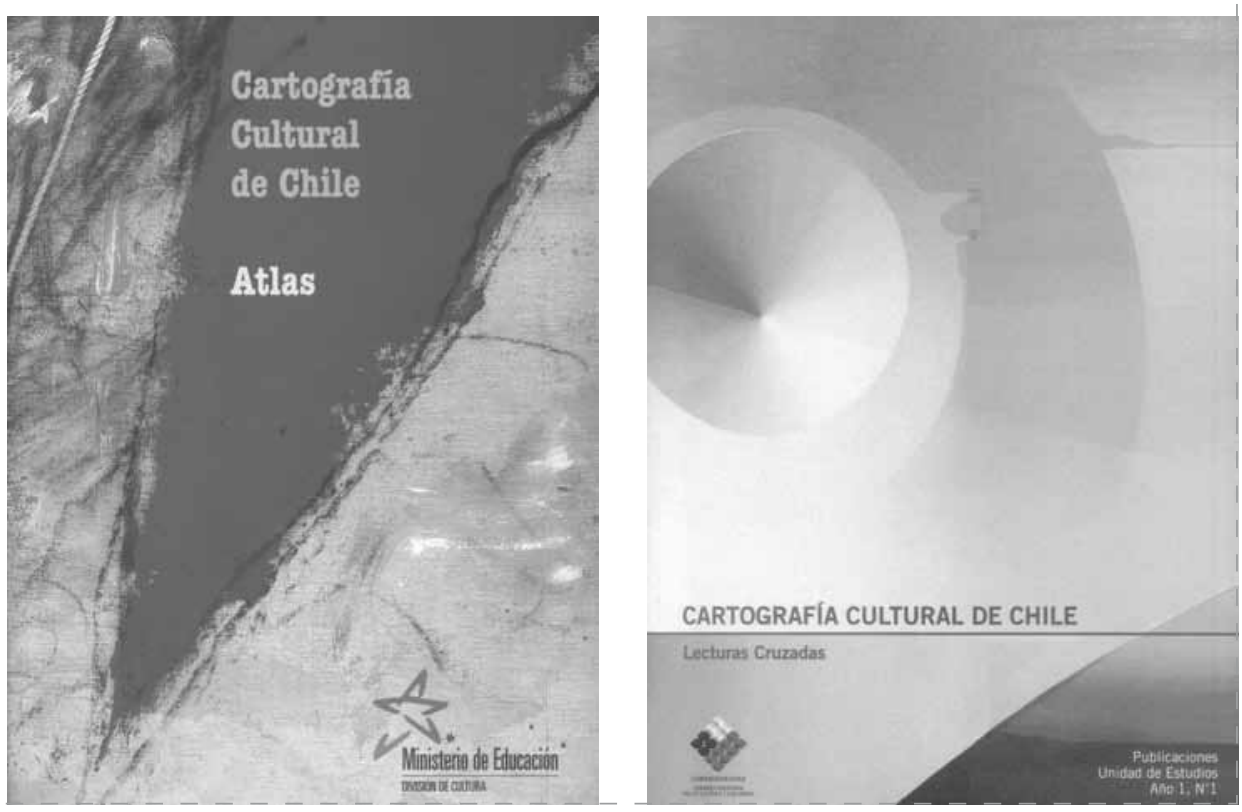

se desarrolla, el que deja su impronta en el producto ${ }^{3}$.

El estudio referido realiza un análisis nacional de la información disponible respecto de los actores culturales, las principales manifestaciones colectivas y los diversos bienes patrimoniales del país. Se dedicó especial atención al registro de actores individuales, ya que las estadísticas actualmente existentes sólo dan una mirada muy gruesa de éstos. La Cartografía fue, pues, una oportunidad única para detenerse en ellos y reflexionar sobre sus características, sirviendo de insumo para la definición de políticas de fomento y apoyo del sector ${ }^{4}$.

Por otra parte, el Patrimonio Natural y Cultural, registra bienes y objetos reconocidos como patrimoniales tanto por las instituciones públicas especializadas, como por las comunidades, habiéndose enumerado al año 2001, 1.581 bienes y objetos patrimoniales.

La apreciación de los bienes desde el nivel local es relevante -tal como se destaca ${ }^{5}$ - pues da cuenta del reconocimiento que tiene la población de sus bienes patrimoniales, "más allá de que estén o no legalizados", y esta conciencia patrimonial induciría a la población a proteger esos mismos bienes.

Un ejemplo de esto se puede encontrar en el caso del estudio del patrimonio arquitectónico de la comuna de Independencia, realizado por especialistas del Instituto de Restauración Arquitectónica de la F.A.U. de la Universidad de Chile, por mandato del nivel local. Se registra en él no sólo los edificios clasificados oficialmente para su protección, sino también aquella arquitectura menor que no destaca por tamaño o por esplendor, pero que contribuye a dar cuerpo, identidad y sentido a algunas vecindades no sólo en tanto estructuras materiales, sino también por ser unidades sociales claramente reconocibles ${ }^{6}$. Un avance sobre este estudio fue realizado en una investigación universitaria para efecto de asociar a los edificios patrimoniales de la comuna -entendidos según se refirió antes-, a los "espacios públicos patrimoniales" 7 .

En la Cartografía Cultural citada, a analizar el tipo de "bienes patrimoniales", destacan los Monumentos Nacionales (registrados por el Consejo de Monumentos Nacionales), representando el $42,7 \%$ del total. El patrimonio local representa el $27,8 \%$ y los monumentos conmemorativos el 23,2\%. El Sistema de Parques Naturales, Protegido por la Corporación Nacional Forestal, representa el 6,3\%.

En este trabajo, los monumentos nacionales incluyen "monumentos históricos, arqueológicos, públicos, santuarios de la naturaleza y zonas típicas".

Por tanto, podemos ver que, al menos, ciertas obras arquitectónicas y conjuntos urbanos están comprendidos en la "Cartografía Cultural de Chile", lo cual supone la existencia y reconocimiento de los actores correspondientes, individuales, o colectivos.

Una nueva investigación del Consejo Nacional de la Cultura y las Artes, titulada "Los Trabajadores del sector cultural en Chile. Estudio de caracterización"8, remite a profesionales o a actores por vocación, desempeñándose individual o colectivamente, para contribuir a crear, reproducir, distribuir, exhibir, comercializar, difundir y conservar las prácticas, los objetos culturales ${ }^{9} \mathrm{y}$ obras artísticas. Es decir, todo aquel que se integre a alguna fase de la "cadena de valorización" de una determinada obra artístico cultural -desde su creación hasta su exhibición ante el público-. Además se incluyó, en términos operativos, a los siguientes "tipos" de individuos: "Creadores,

3 Ibidem.

4 Ibidem.

M. Paulina Soto L., Loreto López G., y Luis Campos M.

ANDUAGA G., Magda; DUARTE G., Patricio; SAHADY V., Antonio. Patrimonio Arquitectónico de la Comuna de Independencia. Santiago: Instituto de Restauración Arquitectónica, F.A.U. de la Universidad de Chile, 1996. 219 págs. ilustradas.

PAVEZ R... M. Isabel (Inv. Responsable); SAHADY V., Antonio; DURÁN A., Martín (Co- Inv.); DUARTE G., Patricio (Col.). El Potencial de Espacios Públicos y Semipúblicos del Pericentro Histórico de Santiago: Recomendaciones Integrales al Trazado Urbano y Arquitectura Patrimoniales en La Comuna De Independencia. Concurso F.A.U. Proyectos de Investigación Arquitectura y Urbanismo, Geografía y Diseño 1999 (duración 1 año, realizada en 2000). Tres Tomos.

8 CHILE - CONSEJO NACIONAL DE LA CULTURA Y LAS ARTES. Los trabajadores del sector cultural en Chile. Estudio de caracterización. Departamento de Estudios y Documentación, Colombia, Economía Cultura 7, Convenio Andrés Bello, noviembre 2004, 131 págs. 
ejecutores o intérpretes"; "Técnicos de apoyo a la producción"; "Productores y gestores culturales"; "Profesores o maestros de alguna disciplina artística" (por tanto, eventualmente investigadores en ella).

Podemos imaginar, así, para las obras de Arquitectura y Urbanismo, a los actores creadores arquitectos (algunos de ellos Premios Nacionales de Arquitectura y de Urbanismo); a los actores técnicos de apoyo a la producción, como son, por ejemplo, los constructores civiles; a los gestores culturales, como es el Colegio de Arquitectos de Chile mediante sus Bienales de Arquitectura y Urbanismo; a los profesores o maestros de la disciplina de la Arquitectura en el nivel de la enseñanza superior.

Observando el objetivo de incluir a los actores principales y secundarios en la metodología, en nuestra profesión no podríamos excluir a los obreros de la construcción, los que con diversos grados de preparación y especialización, también hacen posible la existencia del objeto cultural arquitectónico o urbano.

Cabe destacar en este punto, el aumento explosivo de escuelas de arquitectura en Chile en las últimas dos décadas -42 Escuelas de Arquitectura a la fecha, con el $54,76 \%$ de ubicaciones en Santiago, Valparaíso y Viña

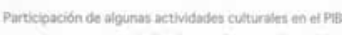

instecudarea y

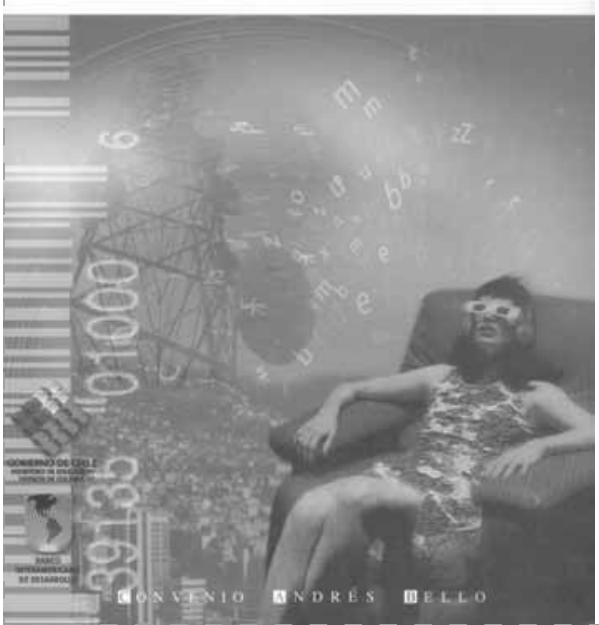

del Mar ${ }^{10}$-, y con ello de arquitectos, y de profesores de arquitectura. Por otra parte, el fast-track o vía rápida para reconocer carreras en Chile y Argentina, a partir del acuerdo bilateral en educación superior suscrito en marzo de 2005, significará un nuevo incremento de los actores culturales arquitectos en Chile ${ }^{11}$. El país cuenta con 9.000 arquitectos en la actualidad ${ }^{12}$, de los cuales casi 8.000 están colegiados ${ }^{13}$. Argentina tiene 40.000 .

Pero, los estudios citados, si bien incorporan a la arquitectura y conjuntos urbanos destacados y reconocidos, al referir el trabajo cultural a las seis áreas de creación antes citadas, de alguna forma dejan fuer a los "trabajadores culturales" de nuestro especial interés, los arquitectos y demás "tipos de individuos" que le acompañan en su labor.

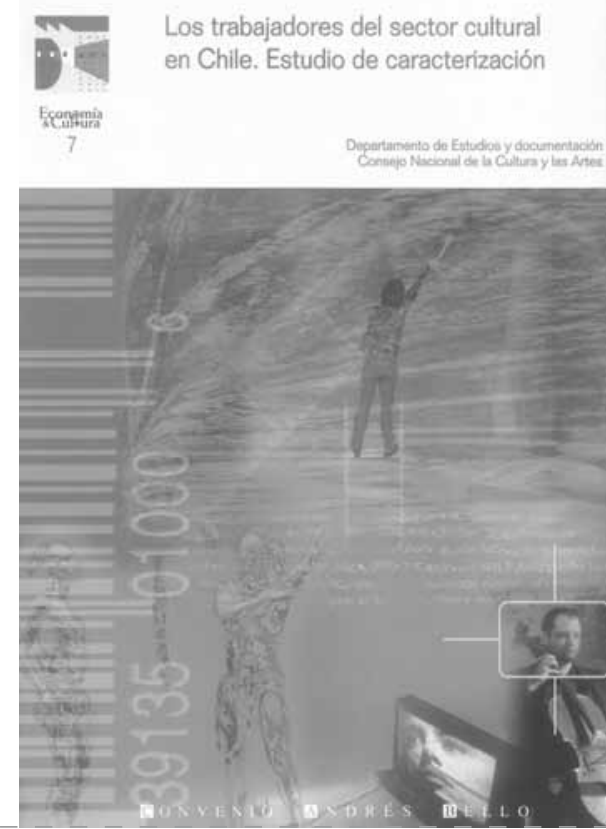

Quedamos pues los arquitectos excluidos en los hechos como actores culturales, aún cuando las obras que han alcanzado cierto nivel de excelencia -y/o han adquirido por su función o circunstancia, un valor histórico- sí se presentan como "bienes patrimoniales"14.

Finalmente, la referida omisión también se manifiesta en el estudio "Impacto de la cultura en la economía chilena. Participación de algunas actividades culturales en el PIB. Indicadores y fuentes disponibles", realizado en $2003^{15}$, donde, por cierto no están ausentes las restricciones de la información en las únicas fuentes con las que se pudo contar, pero donde claramente el sector "construcción" -muy bien informado- no está considerado.

9 Los arquitectos restauradores, con una formación muy especializada, permiten la persistencia en el espacio y en el tiempo de los objetos arquitectónicos y urbanísticos. En la restauración de la Catedral de Santiago, en curso, participan profesionales diversos de alta especialización, que contribuyen de esta forma a la persistencia de este edificio memorable a través del tiempo, a la vez que nos mostrarán esta obra de arte mayor en todo su esplendor, incrementando con ello nuestra cultura.

10 Registro en COLEGIO DE ARQUITECTOS DE CHILE, marzo de 2005.

1 EL MERCURIO (ZÚÑIIGA, Víctor). Acuerdo bilateral en educación superior: Fast-track para reconocer carreras en Chile y Argentina, 15 de marzo de 2005. Nota: El presidente del Colegio de Arquitectos de Chile, José RAMÓN UGARTE, señaló que el gremio de los Arquitectos no fue consultado sobre este protocolo.

2 EL MERCURIO, op. cit.

137.978 colegiados en marzo de 2005, según registro del COLEGIO DE ARQUITECTOS DE CHILE.

14 Nota: Se observa la cita 21 (en p. 26) de la investigación Estudio de caracterización de los trabajadores del Sector Cultural. Educación y Formación de los Trabajadores del Sector Cultural (GOBIERNO DE CHILE, Consejo Nacional de la Cultura y las Artes, Unidad de Estudios, Año 1, №3, 49 págs.), donde se menciona la oferta de "carreras artísticas" en las regiones Metropolitana y Novena (analizadas en este estudio) considerando datos del Consejo Superior de Educación. Así, por ejemplo, en la Región Metropolitana existiría una oferta de 7.718 vacantes anuales incluyendo "arquitectura y derivados", bellas artes y artes visuales, teatro, escenografía y afines, cine y audiovisual, fotografía, gráfica y multimedia, danza y música -sin considerar letras-. Es esta la única vez que se menciona la Arquitectura. Para "carreras artísticas" o con vinculación artística y las "pedagogías artísticas" se alcanza el 74\% en la Región Metropolitana.

15 CHILE - GOBIERNO DE CHILE, MINISTERIO DE EDUCACIÓN, Consejo Nacional de la Cultura y las Artes. Impacto de la cultura en la economía chilena. Participación de algunas actividades culturales en el PIB. Indicadores y fuentes disponibles. Colombia, Economía \& Cultura, Convenio Andrés Bello, noviembre 2003 , 99 págs. 
Se podrá argumentar que no todas las obras arquitectónicas y urbanas llegan a constituirse en Monumentos Nacionales o Zonas Típicas, y no todos los actores correspondientes llegan a obtener los Premios Nacionales, pero lo mismo puede decirse para las obras y los actores de las Artes Visuales y otras referidas, donde también se "está haciendo" la labor continuamente, con productos de diversos grados de calidad, premiados o no, y también con ciertas licencias "mal vistas", como cuando algunos artesanos de Pomaire pintaron sus cántaros con pintura dorada, o como cuando se imita los arcos romanos en arquitectura de hormigón armado.

\section{Reflexión}

Destacamos que el mérito de los estudios e instituciones citadas, más allá de los antecedentes que aportan, es haber comenzado una tarea referida al sector cultural, respecto de la que resta mucho por hacer, como señalan claramente sus autores: hay necesidad de llevar a cabo observaciones sectoriales que permitan rescatar la especificidad de las diversas actividades culturales, de esclarecer "las actividades más industrializadas", y "las menos visibles", lo cual permitiría dibujar un mapa más exacto, que entregue información más completa y con mayor nivel de desagregación que el que presentan las fuentes oficiales hasta ahora, entre muchos otros.

Si los productos culturales arquitectónicos son mucho más que simples objetos bellos -toda vez que son portadores de funciones sociales, económicas, políticas e ideológicas, entre otras-, los arquitectos deberían ser claramente reconocidos como actores culturales. Es posible que la arquitectura depurada de toda fantasía, concentrada en lo utilitario y constructivo, a que han llevado las búsquedas arquitectónicas del gran parte del siglo xx, no logre impresionar el imaginario colectivo como lo ha hecho la arquitectura

1

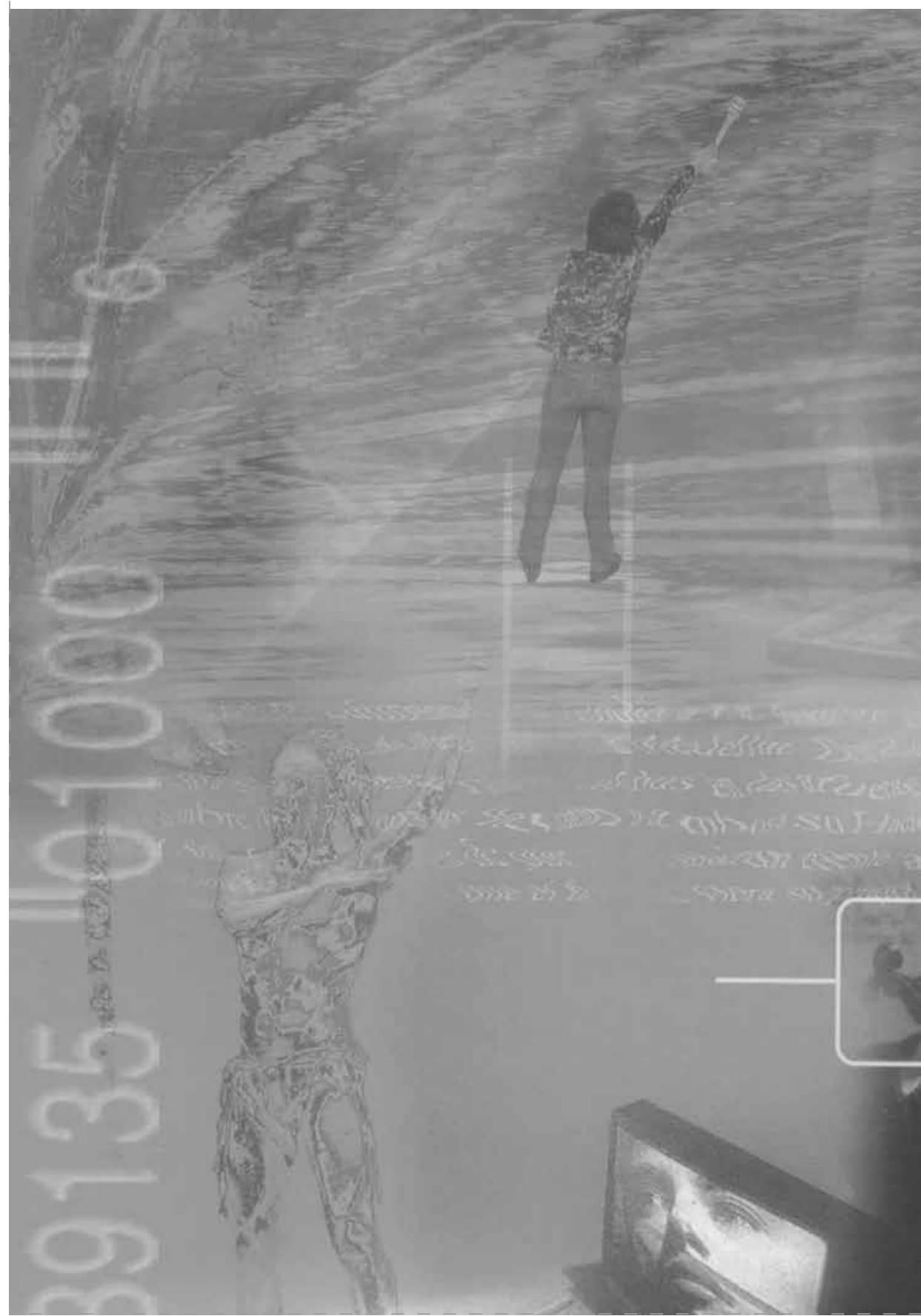

ornamentada. También es posible que la arquitectura del siglo xx, que va sirviendo de excelente soporte de todo tipo de mega-avisos publicitarios sin que a nadie le importe -lo que nunca se permitiría en una escultura-, nos haga desaparecer como creadores respetados de un "arte mayor" ante el habitante común.

Vemos que, de la tarea que el Consejo Nacional de la Cultura y las Artes ha emprendido, los arquitectos no deberíamos restarnos. Tal vez la labor de difusión de nuestras proposiciones ante la comunidad, y no sólo entre especialistas, aún es insuficiente, y cuando existe, sólo refiere viviendas que la gran mayoría de los habitantes jamás podrá ver personalmente, ni menos habitar. 